\title{
Visual impairment and its predictors among people living with type 2 diabetes mellitus at Dessie town hospitals, Northeast Ethiopia: Institution-based cross-sectional study
}

Mohammed Abdu Seid ( $\sim$ mameabdu54@gmail.com )

Debre Tabor University

Adugnaw Ambelu

University of Gondar

Mengistie Diress

University of Gondar

Yigizie Yeshaw

University of Gondar

Yonas Akalu

University of Gondar

Baye Dagnew

University of Gondar

\section{Research Article}

Keywords: Visual impairment, type 2 diabetes mellitus, Ethiopia

Posted Date: December 23rd, 2020

DOl: https://doi.org/10.21203/rs.3.rs-121136/v1

License: (c) (1) This work is licensed under a Creative Commons Attribution 4.0 International License.

Read Full License

Version of Record: A version of this preprint was published at BMC Ophthalmology on February 3rd, 2022. See the published version at https://doi.org/10.1186/s12886-022-02292-3. 


\section{Abstract}

Background: Visual impairment $(\mathrm{VI})$ is a functional limitation of the eye(s) that results in reduced visual acuity, visual field loss, visual distortion, perceptual difficulties, or any combination of the above. Type 2 diabetes mellitus (T2DM) is one of the common causes of visual impairment. No study was conducted in Ethiopia to determine the prevalence of visual impairment and its predictors among people living with T2DM. Therefore, the current study aimed to determine the prevalence and predictors of visual impairment among people living with T2DM at Dessie town Hospitals, Northeast Ethiopia, 2020.

Methods: Institution-based cross-sectional study was carried out from 15 February to 15 March 2020 using simple random sampling technique to recruit study participants among people living with T2DM. Visual impairment was measured using visual acuity test. We used Epi-Data 3.1 and SPSS version 22 for data entry and statistical analysis, respectively. Bi-variable binary logistic regression was performed to check independent association of each factor with visual impairment. After selecting candidate variables at $p<0.25$, we computed multivariable binary logistic regression to identify statistically significant factors of visual impairment. The degree of association was determined using adjusted odds ratio (AOR) with $95 \%$ confidence interval. In the final model, statistical significance was declared at $p \leq 0.05$.

Results: Three hundred and twenty-two people living with T2DM participated in this study with $97 \%$ response rate. The prevalence of visual impairment was 37.58\% (95\% Cl: 32.3, 42.9). Age (AOR: 1.06, 95\% Cl: 1.02, 1.09, $p \leq 0.001)$, poor regular exercise (AOR=2.91, 95\%Cl: 1.47-5.76, $p \leq 0.001)$, duration of $D M$ above 5 years (AOR=2.42, 95\% Cl: 1.25-4.73, $\mathrm{p} \leq 0.01)$, insulin treatment ( $\mathrm{AOR}=14.05,95 \% \mathrm{Cl}: 2.72,72.35$, $\mathrm{p} \leq 0.01)$, and poor glycemic control $(\mathrm{AOR}=2.17,95 \% \mathrm{Cl}: 1.13-4.14, \mathrm{p} \leq 0.05)$ were statistically associated with visual impairment.

Conclusion: The prevalence of visual impairment in Dessie town hospitals accounted for more than a third of patients living with T2DM. Visual impairment is associated with increased age, poor regular exercise, longer duration of DM, and insulin treatment. Thus, early detection of VI through screening and regular follow-up is recommended to reduce the risk of $\mathrm{VI}$ and vision loss.

\section{Background}

Type 2 diabetes mellitus (T2DM) is a devastating metabolic disease, occurring in developed and developing countries (1). Patients with T2DM are highly prone to cardiovascular diseases, renal failure, neurological problems, retinopathy, and visual impairment (2,3). Even though some forms of diabetic retinopathy (i.e. precursor of visual impairment) are restorable, most problems of vision loss are not restorable (1-3). Visual impairment $(\mathrm{VI})$ is a functional limitation of the eye(s) due to different medical problems, including T2DM, that results in reduced visual acuity, visual field loss, visual distortion, perceptual difficulties, or any combination of the above (5). It is presented visual acuity of worse than $20 / 40$ to no light perception (NLP) in either or both eyes (6). Visual impairment can be congenital or hereditary. Causes of VI incudes refractive error, cataract, glaucoma, corneal opacity, age-related macular 
degeneration, diabetic retinopathy (5,7-10), ocular disease, trauma and systemic diseases such as hyperthyroidism (11), rheumatoid arthritis, HIV/AIDS, and hypertension (12).

Unless early preventions made, visual impairment can lead unemployment, reduced productivity, increases medical expense, difficulties in reading and fail to work in order to obtain wages to their family, and execute their social responsibilities as a whole $(7,13)$. People developing visual impairment(s) experience major life changes, such as general health limitations or loss of nearby family member $(1,4)$. They also are at higher risk of violence and abuse which limit them from participating in and contributing to their families and societies on an equal basis with others (14).

Currently around 2.2 billion peoples have visual impairment (7), of which at least 1 billion of VI could have been prevented. Among the causes of visual impairment, $1 \%$ was associated with diabetic retinopathy (i.e. precursor of visual impairment) (16).

Different studies revealed discrepant prevalence of VI among T2DM as observed in Sankara Nethralaya (4\%) (17), Peru (26.3\%) (18), China (10\%) (9), Jordan (17.7\%) (19), Turkey (16.2 \%) (20), and Yemen (76.5\%) (21). In Africa, studies on VI among T2DM showed that 78.25\% in South Africa (22), $17.1 \%$ in Zambia (23), $18.4 \%$ in Ghana (24), 24.1\% in Nigeria (25). Moreover observational studies in Tunisia (26) and Cameron (27) revealed $22.2 \%$ and $22.6 \%$ prevalence of VI among DM patients, respectively.

Visual impairment is associated with increased age, longer duration of DM, higher body mass index, lower educational level, and use of insulin as treatment option $(9,19,28)$. In Sankara Nethralaya, patients aged above 60 years and low socio-economic status (17) whereas a study in Peru revealed the association of VI with hypertension, hemoglobin A1c, and use of insulin (18). Studies in Cameroon, Zambia, Turkey and Tunisia indicated that increased age, overweight, longer duration of DM, poor glycemic control, high systolic blood pressure, and use of insulin as treatment option for DM were significantly associated to $\mathrm{VI}(20,23,26,29)$.

Even though there was one study in Ethiopia that revealed $28.9 \%$ of visual disturbance (not visual impairment) (30), no study is conducted in Ethiopia regarding $\mathrm{VI}$ and its predictors. Therefore, this study aimed to determine the prevalence of $\mathrm{VI}$ and its predictors among people living with T2DM at Dessie Town Hospitals, Northeast Ethiopia, 2020.

\section{Methods}

\section{Study design, setting and period}

This institution-based cross-sectional study was conducted at Dessie town Hospitals (both government and private Hospitals) from 15 February to 15 March 2020. Dessie town is located $400 \mathrm{~km}$ away from Addis Ababa, the capital city of Ethiopia. There were four private and one governmental referral Hospitals in Dessie town. According to annual summative report of all diabetic clinics in Dessie town hospitals, an estimated number of 14,000 people living with T2DM were served. In each Hospital, there was diabetic 
follow-up clinic for people living with DM (10210 clients for Dessie referral Hospital, 1440 clients for Selam general Hospital, 1250 clients for Ethio general hospital and 1100 clients for Bati general Hospital). The follow-up date in each hospital was from Monday to Friday.

\section{Study population and eligibility criteria}

All people living with T2DM visiting diabetic clinic of each Hospital during data collection period were participants and those T2DM who had follow-up and newly diagnosed patients at the same period were included in the study. People living with T2DM who were seriously ill, pregnant women and those who had HIV/AIDS, trachoma, acute eye infections and trauma to the eye and history of head injury, history of stroke were excluded from the study.

\section{Sample size determination and sampling technique}

Sample size was determined using a single population proportion formula with assumptions; $p=0.289$ (30) (proportion of T2DM with visual disturbance) , $95 \% \mathrm{Cl}$, and $5 \%$ margin of error ( $d=0.05)$. The minimum sample size was 316 and the final sample size was 332 after adding $5 \%$ oversampling to account for unpredictable events during data collection.

Samples were recruited using simple random sampling technique (using lottery method) and allocated proportionally to the four hospitals based on the number of T2DM clients at each hospital.

\section{Operational definitions}

Visual impairment: Any loss or abnormality in an anatomical structure or a physiological or psychological function (5). It is presenting visual acuity of worse than 20/40 to no light perception (NLP) in either or both eyes that includes both low vision and blindness (31).

Low vision: Even with corrective lenses, it is inability to clearly see at a distance of 6 meters (20 feet) that individuals with normal vision can clearly see at a distance of 12 meters (40 feet) or visual acuity between 6/12 and 3/60. Low vision includes mild visual impairment (VA between 6/12 and 6/18), 'moderate visual impairment (VA between 6/18 and 6/60)' and 'severe visual impairment (VA between $6 / 60$ and $3 / 60$ )' from all causes (7).

Blindness: Inability to read the largest letter on a vision chart at a distance of 3 meters (10 feet) or visual acuity was worse than $3 / 60(32)$.

Visual acuity/VA: Simple, non-invasive measure of the visual system's ability to discriminate two high contrast points in space. It is usually taken at a distance of $6 \mathrm{~m}$ or 20 feet (16). It is expressed in terms of $A / B$, where $A$ is the distance between observer and letters and $B$ is the expected distance that the normal eye can see. 
Obesity: Body Mass Index (BMI) of $\geq 30 \mathrm{~kg} / \mathrm{m}^{2}$. Subtypes include class 1 obesity (BMl: $30-34.9 \mathrm{~kg} / \mathrm{m}^{2}$ ) class 2 obesity (BMl:35-39.9 kg/m²) class 3 extreme obesity or morbid obesity (BMl: $\left.\geq 40 \mathrm{~kg} / \mathrm{m}^{2}\right)(33$ ).

Exercise: A person who experienced regular exercise below 150 minutes (3-5days) per week was considered as having poor regular exercise otherwise it was considered as having good regular exercise (34).

Regular follow-up: Clients could visit the diabetic clinic of each hospital every 3 months.

\section{Data collection instrument, procedure and quality control}

Pre-tested, semi-structured-interviewer-administered questionnaire containing Socio-demographic variables, behavioral variables (diet, exercise and regular follow-up), clinical related variables (glycemic control, plasma glucose level, duration of DM, treatment option for DM, and presence of comorbidities such as hypertension and/or obesity) were used to collect data. Study participants were scheduled for eye examination at the eye clinic of the same institution on the same day. The participants had gotten counseling, care and referral depending on the ocular findings. We used tape meter, and weight balance for measuring height and weight, respectively. Each participant had visual acuity assessment with illuminated Snellen's chart for each eye at 6 meter. Training was given to data collectors and the supervisor by principal investigator about the objectives of the study, data collection techniques and ethical issues. Data collectors were four (2 BSc ophthalmic Nurses and 2 BSc Nurses) and one supervisor (BSc Public health). Strict supervision was taken during data collection process.

\section{Reliability and validity}

The Cronbach's alphas for this study was below 0.5 which is due to the questionnaires were selfdeveloped and unstandardized. Content validity was ensured by pre-testing the data collection tool on 17 students out of the study area. The tool was modified based on the observed findings from the pre-test result. Some questions having ambiguous meaning were rewritten for better understanding of study participants.

\section{Data processing and statistical analysis}

Data were entered into Epi-Data 3.1 and exported into SPSS 22 for statistical analysis. Continues data were described by median and interquartile range (IQR) whereas frequency with percent was used to describe categorical variables. Bi-variable binary logistic regression analysis was performed to select potential candidate variables for the final model with cut-off point of $p$-value $\leq 0.25$ (35). Multivariable binary logistic regression analysis was executed to identify predictors of visual impairment. The measure of association was described by crude odds ratio (COR) and adjusted odds ratio (AOR) with their $95 \% \mathrm{Cl}$. In the final model, variables with a $p$-value $\leq 0.05$ were considered as statistically significant. Model fitness was checked by Hosmer and Lemeshow goodness of fit test (at $p>0.05$ ) and multicollinearity was tested by VIF. 


\section{Results}

Three hundred and twenty-two people living with T2DM participated in the study yielding a response rate of $97 \%$. The median age of participants was 52 years (IQR: $45-60$ years). One hundred and seventy-five $(54.3 \%)$ study participants were males with female to male ratio of $1: 1.18$. Two hundred and twelve (65.8\%) individuals were Islam religion followers. Seventy-three (22.7\%) participants did not attend formal education. One hundred and fifteen (35.7\%) were employed in the private organization, 291 (90.4\%) were married, and 249 (77.3\%) were urban dwellers. The participants claim a median monthly income of 3570 Ethiopian birr (ETB) (IQR: 2000-5195, Min = 800 and Max = 9600 ETB) (Table 1). 
Table 1

Socio-demographic characteristics of people living with T2DM at Dessie town Hospitals, Northeast Ethiopia, $2020(n=322)$

\begin{tabular}{|c|c|c|c|}
\hline Variables & Categories & Frequency & Percent \\
\hline \multirow[t]{3}{*}{ Age in years } & $20-40$ & 37 & 11.5 \\
\hline & $41-59$ & 189 & 58.7 \\
\hline & $60-87$ & 96 & 29.8 \\
\hline \multirow[t]{2}{*}{ Sex } & Male & 175 & 54.3 \\
\hline & Female & 147 & 45.7 \\
\hline \multirow[t]{3}{*}{ Religion } & Muslim & 212 & 65.8 \\
\hline & Orthodox & 103 & 32 \\
\hline & Others* & 7 & 2.2 \\
\hline \multirow[t]{2}{*}{ Marital status } & Never married & 31 & 9.6 \\
\hline & Married & 291 & 90.4 \\
\hline \multirow[t]{2}{*}{ Residence } & Urban & 249 & 77.3 \\
\hline & Rural & 73 & 22.7 \\
\hline \multirow[t]{4}{*}{ Educational level } & No formal education & 73 & 22.7 \\
\hline & Primary & 84 & 26.1 \\
\hline & Secondary & 79 & 24.5 \\
\hline & Diploma and above & 86 & 26.7 \\
\hline \multirow[t]{5}{*}{ Occupation } & Government workers & 70 & 21.8 \\
\hline & Private workers ** & 115 & 35.7 \\
\hline & Farmer & 37 & 11.5 \\
\hline & House wife & 60 & 18.6 \\
\hline & Others*** & 40 & 12.4 \\
\hline
\end{tabular}

Forty six (14.3\%) people living with T2DM had trouble in adjusting light while entering from bright to dim light. One hundred and seventy-three (53.7\%) participants experienced a duration of 5 years and lower since diagnosis whereas $24(7.5 \%)$ were new cases. Two hundred and sixty-four (82.0\%) had regular 
follow-up for T2DM in the selected hospitals. One hundred and ninety-nine (61.8\%) participants had poor regular physical exercise. The treatment option for DM was oral hypoglycemic agents without insulin among 201 (62.4\%) people living with T2DM. Thirty seven (11.5\%) participants were obese (BMl: median = 34.8, IQR: (23.1-27.65) and 98 (30.4\%) individuals had co-morbid hypertension. The median of baseline random plasma glucose was $311 \mathrm{mg} / \mathrm{dl}$ (IQR: $260-396 \mathrm{mg} / \mathrm{dl}$ )) and fasting plasma glucose was $160 \mathrm{mg} / \mathrm{dl}$ (IQR: 140-208 mg/dl), respectively. One hundred and eighty-seven (58.1\%) participants had poor glycemic control (Table 2).

Table 2

Factors related to Diabetes mellitus and vision-related characteristics of participants at Dessie town Hospitals, Northeast Ethiopia, $2020(n=322)$

\begin{tabular}{|c|c|c|c|}
\hline Variables & Categories & Frequency & Percent \\
\hline \multirow[t]{2}{*}{ Have trouble in adjusting light (night blindness) } & Yes & 46 & 14.3 \\
\hline & No & 276 & 85.7 \\
\hline \multirow[t]{2}{*}{ Regular follow-up } & Yes & 264 & 82 \\
\hline & No & 58 & 18 \\
\hline \multirow[t]{3}{*}{ Duration of diabetes (in years) } & Newly diagnosed & 24 & 7.5 \\
\hline & $\leq 5$ years & 173 & 53.7 \\
\hline & $>5$ up to 24 years & 125 & 25.8 \\
\hline \multirow[t]{3}{*}{ Treatment $(n=296)$} & OHA without insulin & 201 & 67.9 \\
\hline & Both of OHA and insulin & 73 & 24.7 \\
\hline & Insulin only & 22 & 7.4 \\
\hline \multirow[t]{2}{*}{ Regular exercise } & Good* & 123 & 38.2 \\
\hline & Poor* & 199 & 61.8 \\
\hline \multirow[t]{4}{*}{ BMI $\left(k g / m^{2}\right)$} & Underweight & 5 & 1.5 \\
\hline & Normal & 159 & 49.4 \\
\hline & Overweight & 121 & 37.6 \\
\hline & Obese & 37 & 11.5 \\
\hline \multirow[t]{2}{*}{ Comorbid hypertension } & Yes & 98 & 30.4 \\
\hline & No & 224 & 69.6 \\
\hline \multirow[t]{2}{*}{ Glycemic control } & $<152$ mg/dl (good) & 135 & 41.9 \\
\hline & $\geq 152 \mathrm{mg} / \mathrm{dl}$ (poor) & 187 & 58.1 \\
\hline
\end{tabular}




\section{Prevalence of visual impairment among people living with T2DM}

In the current study, the prevalence of visual impairment was $37.58 \%$ [95\% Cl: $32.3-42.9 \%$ ]. Among the overall prevalence of visual impairment, $43(35.5 \%)$ had bilateral vision impairment and $78(64.5 \%)$ had monocular vision impairment. Of all visually impaired T2DM, 107 (88.4\%) and 14 (11.6\%) had low vision and blindness, respectively (Table 3 ).

Table 3

Forms of visual impairment categories among people living with T2DM at Dessie town Hospitals, Northeast Ethiopia, 2020, $(n=322)$

\begin{tabular}{|llll|}
\hline Visual impairment category & & Frequency & Percent \\
\hline$<6 / 12-6 / 18$ & Bilateral mild VI & 28 & 23.1 \\
\hline$<6 / 18-6 / 60$ & Bilateral moderate VI & 10 & 8.3 \\
\hline$<6 / 60-3 / 60$ & Bilateral severe VI & 1 & 0.8 \\
\hline$<3 / 60-\mathrm{NLP}$ & Bilateral blindness & 4 & 3.3 \\
\hline$<6 / 12-6 / 18$, other eye 6/6-6/12 & Monocular mild VI & 0 & 0.0 \\
\hline$<6 / 18-6 / 60$, other eye 6/6-6/18 & Monocular moderate VI & 48 & 39.7 \\
\hline$<6 / 60-3 / 60$, other eye 6/6-6/60 & Monocular severe VI & 20 & 16.5 \\
\hline$<3 / 60-N L P$, other eye 6/6 $-3 / 60$ & Monocular blindness & 10 & 8.3 \\
\hline Total & & 121 & 100 \\
\hline Note: NLP-no light perception, VI-visual impairment & & \\
\hline
\end{tabular}

\section{Predictors of $\mathrm{VI}$ among people living with T2DM}

Age, sex, marital status, educational level, occupation, residence, regular physical exercise, duration of $\mathrm{DM}$, treatment option for $\mathrm{DM}$, baseline random plasma glucose, co-morbid hypertension, and glycemic control were independently associated with $\mathrm{VI}$ in the bivariable binary logistic regression. After running the aforementioned variables in the multivariable binary logistic regression; increased age, poor regular physical exercise, longer duration of T2DM, use of insulin as treatment option for DM and, poor glycemic control were statistically significant with VI.

The odds of having VI for each age increase of a unit was 1.06 times (AOR: 1.06, 95\% Cl: 1.02, 1.09). Participants who relied on insulin as treatment option for DM were 14 times (AOR $=14.05,95 \%$ Cl: 2.72, 72.35) more likely to get $\mathrm{VI}$ than those who used treatment options without insulin. The odds of having $\mathrm{VI}$ was 2.91 times (AOR $=2.91,95 \% \mathrm{Cl}: 1.47,5.76)$ higher among those who had poor physical exercise than those who were good in regular physical exercise. People living with T2DM for a duration of more than 5 years were 2.42 times (AOR: $2.42,95 \% \mathrm{Cl}: 1.24,4.73$ ) more likely to acquire $\mathrm{VI}$ than those with duration 
of 5 years and below. Those who had poor glycemic control were 2.17 times (AOR: 2.17, 95\% Cl: 1.13, 4.14) more likely to develop $\mathrm{VI}$ as compared to those who had good glycemic control (Table 4). 
Table 4

Multivariable binary logistic regression analysis for predictors of visual impairment among people living with T2DM at Dessie town Hospitals, Northeast Ethiopia, $2020(n=322)$

\begin{tabular}{|c|c|c|c|c|c|}
\hline \multirow[t]{2}{*}{ Variables } & \multirow[t]{2}{*}{ Categories } & \multicolumn{2}{|c|}{$\begin{array}{l}\text { Visual } \\
\text { impairment }\end{array}$} & \multirow{2}{*}{$\begin{array}{l}\text { OR } \\
\text { COR }(95 \% \mathrm{Cl})\end{array}$} & \multirow[t]{2}{*}{ AOR(95\% Cl) } \\
\hline & & No & Yes & & \\
\hline \multirow[t]{2}{*}{ Sex } & Male & 119 & 56 & 1 & 1 \\
\hline & Female & 82 & 65 & $1.68(1.06,2.65)$ & $1.29(0.56,2.96)$ \\
\hline \multirow[t]{2}{*}{ Marital status } & Unmarried & 27 & 4 & 1 & 1 \\
\hline & Married & 174 & 117 & $\begin{array}{l}4.54(1.54 \\
13.31)\end{array}$ & $1.25(0.30,5.11)$ \\
\hline \multirow[t]{4}{*}{ Education } & $\begin{array}{l}\text { Unable to read and } \\
\text { write }\end{array}$ & 32 & 41 & 1 & 1 \\
\hline & Primary & 52 & 32 & $0.48(0.25,0.90)$ & $0.92(0.332 .50)$ \\
\hline & Secondary & 51 & 28 & $0.43(0.22,0.82)$ & $1.11(0.37,3.29)$ \\
\hline & Diploma and above & 66 & 20 & $0.23(0.12,0.46)$ & $0.67(0.20,2.23)$ \\
\hline \multirow[t]{5}{*}{ Occupation } & Government worker & 52 & 18 & 1 & 1 \\
\hline & Private worker & 81 & 34 & $1.21(0.62,2.36)$ & $0.80(0.34,1.88)$ \\
\hline & Farmer & 23 & 14 & $1.75(0.74,4.12)$ & $0.35(0.10,1.17)$ \\
\hline & House wife & 26 & 34 & $3.77(1.80,7.92)$ & $1.54(0.59,4.00)$ \\
\hline & Other & 19 & 21 & $3.19(1.40,7.25)$ & $1.33(0.42,4.17)$ \\
\hline \multirow[t]{2}{*}{ Residence } & Urban & 166 & 83 & 1 & 1 \\
\hline & Rural & 35 & 38 & $2.17(1.27,3.68)$ & $1.85(0.71,4.80)$ \\
\hline \multirow{2}{*}{$\begin{array}{l}\text { Regular- } \\
\text { exercise }\end{array}$} & Good & 94 & 29 & 1 & 1 \\
\hline & Poor & 107 & 92 & $2.78(1.68,4.59)$ & $\begin{array}{l}2.91(1.47 \\
5.76)^{\star \star}\end{array}$ \\
\hline \multirow{2}{*}{$\begin{array}{l}\text { Duration of } \\
\text { diabetes }\end{array}$} & $\leq 5$ years & 154 & 43 & 1 & 1 \\
\hline & $>5-24$ years & 47 & 78 & $\begin{array}{l}28.59(3.68 \\
221.75)\end{array}$ & $\begin{array}{l}2.42(1.24 \\
4.73) \star \star\end{array}$ \\
\hline \multirow[t]{3}{*}{ Treatment } & $\mathrm{OHA}$ without insulin & 140 & 61 & 1 & 1 \\
\hline & $\begin{array}{l}\text { Both of } \mathrm{OHA} \text { and } \\
\text { insulin }\end{array}$ & 34 & 39 & $2.63(1.52,4.56)$ & $1.45(0.71,2.97)$ \\
\hline & Insulin only & 2 & 20 & $\begin{array}{l}22.95(5.20 \\
101.25)\end{array}$ & $\begin{array}{l}14.05(2.72 \\
72.35)^{\star \star}\end{array}$ \\
\hline
\end{tabular}




\begin{tabular}{|c|c|c|c|c|c|}
\hline \multirow[t]{2}{*}{ Variables } & \multirow[t]{2}{*}{ Categories } & \multicolumn{2}{|c|}{$\begin{array}{l}\text { Visual } \\
\text { impairment }\end{array}$} & \multirow{2}{*}{$\begin{array}{l}\text { OR } \\
\text { COR }(95 \% \mathrm{Cl})\end{array}$} & \multirow[t]{2}{*}{ AOR(95\% Cl) } \\
\hline & & No & Yes & & \\
\hline \multirow[t]{2}{*}{ Hypertension } & Yes & 51 & 47 & $1.86(1.15,3.03)$ & $1.26(0.65,2.44)$ \\
\hline & No & 150 & 74 & 1 & 1 \\
\hline Glycemic & $<152$ (good) & 94 & 41 & 1 & 1 \\
\hline Control (FPG) & $\geq 152$ (poor) & 107 & 80 & $1.71(1.07,2.73)$ & $2.17(1.13,4.14)^{\star}$ \\
\hline
\end{tabular}

\section{Discussion}

Despite the diverse impact of T2DM on vision, no comprehensive study was conducted in Ethiopia yet to describe visual impairment and factors affecting it among people living with T2DM in Ethiopia. This study was intended to determine the prevalence of visual impairment and identifying its predictors among people living with T2DM at Dessie town Hospitals, Northeast Ethiopia.

In the current study, the prevalence of visual impairment among people living with T2DM was $37.58 \%$ (95\% Cl: 32.3-42.9) at Dessie town Hospitals. This finding is higher than previous study at Dessie referral Hospital which was $28.9 \%$ (30). This difference is probably due to the type of study design used by previous researchers such as review of patient records as source of data, study population difference ( only newly diagnosed DM) and visual disturbance was detected by clinical findings and questionnaire based approaches (where visual acuity test was not applied for the former study). Moreover, the prevalence of visual impairment in the current study is higher than other studies in Nigeria (24.1\%) (36), Tunisia (22.2\%) (26), Cameron (29.7\%) (29), Ghana (18.4\%) (24), Zambia (17.1\%) (23), Turkey (13.5\%) (20), Peru (40.2\%) (18), Jordan (17.7\%) (19), Southern China (10\%) (31), and Sankara Nethralaya (4.1\%) (17). This discrepancy is most likely due to differences in the case definition, socio-economic, and quality of chronic disease care service. In our study, the cut-off point was $V A<6 / 12$ to define VI while $V A<6 / 18$ was used to define $\mathrm{VI}$ for the above listed studies. Those studies used the better eye presenting visual acuity to define visual impairment unlike the present study. Moreover the other studies were conducted at the community level where chance of screening normal sighted people existed. In contrary to this, our study was hospital-based where most patients came with noted diabetic complication which may lead to increased prevalence of VI. Nigerian study applied volunteer sampling and smaller sample size. In Tunisia, purposive sampling was carried out which might introduce bias and both studies used the better eye presenting visual acuity to define VI. If one eye was visually impaired and the other was not impaired, 
they considered as no VI which could underestimate the magnitude of VI compared to our study which is done by considering either eye's visual acuity

The prevalence of unilateral visual impairment in this study is lower than studies done in Yemen (76.5\% (21) and south Africa (78.25\%) (22). This variation might be due to differences in the case definition of VI and sample size. Study participants were T2DM with an age of 40 years and above with a cut-off point of VA between 6/9.5 and 6/18 which was defined as a VI for the study conducted in South Africa while the large sample size was used in Yemen with all conditions overestimate or had possibilities to add additional visually impaired cases.

In the current study increased age, poor regular exercise, longer duration of T2DM, use of insulin as treatment option, and poor glycemic control were predictors (statistically significant) of VI. The odds of having VI for each age increase of a unit was 1.06 times This is similar to a study in Tunisia (26), Southern China (9), and Sankara Nethralaya (17). Possible reasons for this might be with advanced age there might be decreased in physical exercise, loss of muscle mass, and gain weight that in turn fatty cells had more resistant for insulin that increase hyperglycemia. Furthermore, advanced age has potential risk of macrovascular events due to cardiac insufficiency (37).

The odds of having $\mathrm{VI}$ among people living with T2DM who had poor physical exercise was 2.91 times more likely than those who reported good physical exercise. This might be due to exercise can promote an increase in the bioavailability of nitric oxide which decrease blood pressure, post exercise can increase glycolipid uptake and utilization which improves glucose homeostasis, insulin sensitivity, and maintaining glycemic level (38-40), optimized body mass index and modulated DNA methylation (41).

Participants with duration of diabetes of above 5 years was 2.42 times more likely to get visual impairment as compared to those with type 2 diabetes duration of 5 years and below. This finding is in line with Zambia (23), Yemen (28), Peru (18), and China (9). The possible reason might be longer duration of T2DM might reduce adherence to self-care (42), hall marker for long-term exposure to hyperglycemia (43) and potentially increases risk of macrovascular and microvascular events and death (37). Moreover, longer duration is linked to a reduction in insulin secretion or excessive insulin resistance in people living with T2DM (44).

People living with T2DM who relied on insulin only as treatment option were 14 times more likely to get $\mathrm{VI}$ than those who used oral hypoglycemic agents without insulin. This is consistence with studies in Zambia (23), Turkey (20), Peru (18), Jordan (19), and Sankara Nethralaya (28). The reason is probably linked to the use of insulin alone that reflects less adherence (42) resulting in deterioration in kidney function, decline $\beta$-cell function or increase insulin resistance over time (45) which is associated with poor plasma glucose control and higher risk of severe diabetes.

The odds of being visually impaired was 2 times higher among participants with poor glycemic control in contrary to good glycemic control which is in line with study in Peruvian (18). The possible reason might be poor glycemic control or persistent hyperglycemia damages retinal vasculature via activation of pro- 
inflammatory mediators such as tumor necrotic factor (TNF)-2, interleukin-6, interleukin-1b, angiotensin II, endothelin-1, and vascular endothelial growth factor (VEGF) that could alter retinal blood barrier leads to retinal vessel leakage causing macular edema and nerve scaring which result in retinal detachment and sudden vision loss.

\section{Limitations Of The Study}

Since the study was cross sectional, it could not show cause-effect relationship. Recall and social desirability biases were also be possible limitations. Categorization of VA was based on presenting, not corrected visual acuity. HbA1c was not measured due to clients' financial issue so that physicians ordered fast plasma glucose instead of $\mathrm{HbA} 1 \mathrm{c}$. The $\mathrm{HbA} 1 \mathrm{C}$ test is a reliable blood test that provides information about a person's average levels of blood glucose over the past 3 months. However, the fasting plasma glucose shows only point in time result of the diabetic patients.

\section{Conclusion}

The prevalence of $\mathrm{VI}$ in Dessie town hospitals accounts for more than a third of patients living with T2DM that implied a significant public health problem. Older age, poor regular physical exercise, longer duration of T2DM, use of insulin as treatment option for DM, and poor glycemic control were predictors of $\mathrm{VI}$ among people living with T2DM. Regular diabetes follow-up and visual screening for all people living with T2DM should be done at older age group patients and for those having longer duration of DM which can reduce visual morbidity and vision loss. Patients should control glycemic level by taking medications and through adequate and regular physical exercise. Public health policies with educational programs and promotion of DR screening of all T2DM are needed and timely management of DR that greatly reduce the incidence of visual impairment due to diabetes.

\section{List Of Abbreviations}

AOR: Adjusted Odds Ratio, BMI: Body Mass Index, BSc: Bachelor of Science, Cl: Confidence Interval, COR: Crude Odds Ratio, DM: Diabetes Mellitus, DR: Diabetic retinopathy, FPG: Fasting Plasma Glucose, HIV/AIDS: Human Immune Virus/Acquired Immune Deficiency Syndrome, IQR: Inter Quartile Range, NLP: No Light Perception, RPG: Random Plasma Glucose, SPSS: Statistical Package for Social Sciences, SRS: Simple random sampling, T2DM: Type 2 diabetes mellitus, VA: Visual acuity, VEGF: Vascular Endothelial Growth Factor, VI: Visual impairment, VIF; Variance Inflation Factor

\section{Declarations}

\section{Ethics approval and consent to participate}

All the ethical issues were secured according to the declaration of Helsinki. Ethical clearance was obtained from the Institutional Review Board (IRB) of the University of Gondar with a reference number 1839/02/2020, College of Medicine and Health Sciences. Official permission letter was obtained from 
Dessie Town Hospitals prior to data collection and written informed consent was obtained from each study participant. Any identifiable issues were eliminated to keep confidentiality.

\section{Consent for publication}

Not applicable

\section{Availability of data and materials}

The dataset of this research is available at the corresponding author and can be obtained with reasonable request.

\section{Competing interests}

All authors declared that there is no competing of interest

\section{Funding}

No funding was obtained from governmental or nongovernmental organizations.

\section{Authors' contribution}

MA: Conceptualization, data curation, formal analysis, investigation, methodology, resources, software, validation, writing original draft.

AA: Conceptualization, data curation, formal analysis, investigation, methodology

MD: Data curation, formal analysis, validation, reviews and edits the manuscript draft

YY: Analysis, conceptualization, formal analysis, validation, reviews and edits the manuscript draft

YA: Analysis, formal analysis, validation, reviews and edits the manuscript draft

BD: Conceptualization, data curation, formal analysis, investigation, methodology, resources, software, validation, review and edit the manuscript draft.

All authors read and approve the manuscript for submission.

\section{Acknowledgements}

Authors are very grateful to acknowledge the University of Gondar for allowing us to conduct the study. We also appreciate Dessie town Hospital administrators, study participants, data collectors, and the supervisor.

\section{References}


1. World Health Organisation. Global report on diabetes mellitus. 2018; 35-43. http://www.who.int

2. Sayin N, Kara N, Pekel G. Ocular complications of diabetes mellitus. World J disbetes. 2015;6(1):92108. http://www.wjgnet.com/esps/helpdesk.aspx

3. Brownlee M. Biology of diabetic complications. Insight Rev Artic. 2001; 414(13):813-20.

4. A. S. Fauci, D. L. Kasper DLL et al. Harrison's: Principles of Internal Medicine. 20th editi. Vol. 112, the British Journal of Psychiatry. New York, NY, USA: McGraw-Hill; 2018. 211-12 p. www.accessmedicine.com/harrisons.

5. Fraser Freeman K, Author Roy Gordon Cole P, Eleanor Faye OE, Freeman PB, Gregory Goodrich OL, Stelmack JA, et al. Optometric clinical practice guideline care of the patient with visual impairment. Am Optom Assoc. 2007 ; (10):6-8.

6. Maberley DAL, Hollands H, Chuo J, Tam G. The prevalence of low vision and blindness in Canada. Eye. 2006; 10(20):341-6.

7. WHO. World report on vision. 2019; 5-29. http://apps.who.int/iris

8. Flaxman SR, Bourne RRA, Resnikoff S, Ackland P, Braithwaite T, Cicinelli M V, et al. Global causes of blindness and distance vision impairment: a systematic review and meta-analysis. Lancet Glob Heal. 2017; 5(12):1221-34. http://dx.doi.org/10.1016/ S2214-109X (17)30393-5

9. Cui Y, Zhang L, Zhang M, Yang X, Zhang L, Kuang J. Prevalence and causes of low vision and blindness in a Chinese population with type 2 diabetes: the Dongguan Eye Study. Sci Rep. 2017; 7(8):1-9. http://dx.doi.org/10.1038/s41598-017-11365-z

10. WHO. Global initiative for the elimination of avoidable blindness. Vis 2020 , the right to sight. $2007 ;($ 2006-11).

11. Pinazo-durán MD, Zanón-moreno V, García-medina JJ, Arévalo JF, Gallego-pinazo R, Nucci C. Eclectic Ocular Comorbidities and Systemic Diseases with Eye Involvement. Biomed Res Int. 2016; 16:1-7. http://www.hindawi.com

12. Lenake M, Sa F, Registrar S. The eye in systemic disease. S Afr Fam Pr. 2014; 56(1):8-14.

13. Eckert KA, Carter MJ, Lansingh VC, Wilson DA, João M, Frick KD, et al. A Simple Method for Estimating the Economic Cost of Productivity Loss Due to Blindness and Moderate to Severe Visual Impairment. Ophthalmic Epidemiol. 2015; 22(5):349-55. http://www.tandfonline.com/loi/iope20\%0AA

14. M K. Experiences of childhood sexual abuse among visually impaired adults in Norway:Prevalence and characteristics. J Vis Impair Blind. 2005; 99(01):9-11.

15. Bourne RRA, Flaxman SR, Braithwaite T, Cicinelli M V, Das A, Jonas JB, et al. Magnitude, temporal trends, and projections of the global prevalence of blindness and distance and near vision impairment. Lancet Glob Heal. 2015 ;( 17):1-10. http://dx.doi.org/10.1016/S2214-109X (17)30293-0

16. WHO. Global data on visual impairments. 2010; 3-6. http://www.who.int

17. Sankara M, Diabetic N. Prevalence of Visual Impairment and Associated. Middle East Afr J Ophthalmol. 2012; 19(8):129-35. 
18. Villena JE, Yoshiyama CA, Sánchez JE, Hilario NL, Merin LM. Prevalence of diabetic retinopathy in Peruvian patients with type 2 diabetes. Rev Panam Salud Publica. 2011;30 (5):408-14.

19. Ajlouni KM. Prevalence of blindness and visual impairment among Jordanian diabetics. Eur $J$ Ophthalmol.2005; 15 (1):62-8. mahaamr@hotmail.com

20. Idil A, Caliskan D, Ocaktan E. The prevalence of blindness and low vision in older onset diabetes mellitus and associated factors: A community-based study. Eur J Ophthalmol. 2004; 14 (4):298305. caliskan@medicine.ankara.edu.tr

21. Bamashmus MA, Gunaid AA, Khandekar RB. Diabetic retinopathy, visual impairment and ocular status among patients with diabetes mellitus in Yemen: A hospital-based study. Indian J Ophthalmol. 2009; 57(December):293-8.

22. Mabaso RG, Oduntan OA. Prevalence and causes of visual impairment and blindness among adults with diabetes mellitus aged 40 years at government health facilities in the Mopani District, South Africa. ISSN 0378-9411 9. 2014;73(1):8-15. mabaso@mweb.co.za/oduntanoa@ukzn.ac.za

23. Lewis AD, Hogg RE, Chandran M, Musonda L, North L, Chakravarthy U, et al. Prevalence of diabetic retinopathy and visual impairment in patients with diabetes mellitus in Zambia. Eye. 2018; 32(1):1201-8. http://dx.doi.org/10.1038/s41433-018-0055-x

24. Lartey SY, Aikins AK. Visual impairment amongst adult diabetics attending a tertiary outpatient clinic,Kumasi,Ghana. Ghana Med J. 2018; 52(2):84-7. http://dx.doi.org/10.4314/gmj.v52i2.4

25. Kyari F, Tafida A, Sivasubramaniam S, Murthy GVS, Peto T. Prevalence and risk factors for diabetes and diabetic retinopathy: results from the Nigeria national blindness and visual impairment survey. BMC Public Health. 2014;14(1):1-12. http://www.biomedcentral.com/14712458/14/1299\%0aresearch

26. Kahloun R, Jelliti B, Zaouali S, Attia S. Prevalence and causes of visual impairment in diabetic patients in Tunisia , North Africa. Eye. 2014;28(8):986-91.

27. Ayukotang EN, Kumah DB, Mohammed AK. Prevalence of visual impairment among diabetic patients in the Kumba urban area, Cameroon. Int J Innov Appl Stud. 2016;15(4):872-6. http://www.ijias.issrjournals.org/

28. Bamashmus MA, Gunaid AA, Khandekar RB. Diabetic retinopathy , visual impairment and ocular status among patients with diabetes mellitus in Yemen: A hospital-based study. Indian J Ophthalmol. 2004;57(4):293-8.

29. Jingi AM, Nansseu JRN, Noubiap JJN, Bilong Y, Ellong A. Diabetes and visual impairment in subSaharan Africa. J Diabetes Metab Disord. 2015;14(21):1-8.

30. Abejew AA, Belay AZ, Kerie MW. Diabetic Complications among Adult Diabetic Patients of a Tertiary Hospital in Northeast Ethiopia. Adv Public Heal Table. 2015;10(1):1-8. http://dx.doi.org/10.1155/2015/290920

31. Cui Y, Zhang L, Zhang M, Yang X, Zhang L, Kuang J. Prevalence and causes of low vision and blindness in a Chinese population with type 2 diabetes. Sci Rep. 2017;7(August):1-9. http://dx.doi.org/10.1038/s41598-017-11365-z 
32. Clinic E, Do A. Prevalence and Causes of Visual Impairment among Patients in Juaben Hospital. Mathews J Ophthalmol. 2017;2(2):17. www.mathewsopenaccess.com\%0Aducted

33. Obesity N, Initiative E. Guide Identification, Evaluation, and Treatment of Overweight and Obesity in Adults. 2000. 11 p.

34. Colberg SR, Sigal RJ, Fernhall B, Regensteiner JG, Blissmer BJ, Rubin RR, et al. Exercise and type 2 diabetes: The American College of Sports Medicine and the American Diabetes Association: Joint position statement. Diabetes Care. 2010;33(12):e150. care.diabetesjournals.org

35. Bursac Z, Gauss CH, Williams DK, Hosmer DW. Source Code for Biology and Purposeful selection of variables in logistic regression. bioMed Cent. 2008;8(17):1-8. http://www.scfbm.org/content/3/1/17

36. Onakpoya $\mathrm{OH}$, Kolawole BA, Adeoye AO, Adegbehingbe BO, Laoye O. Visual impairment and blindness in type 2 diabetics. Int Ophthalmol. 2015;(Dm):1-9.

37. Zoungas S, Woodward M, Li Q, Cooper ME, Hamet P, Harrap S, et al. Impact of age, age at diagnosis and duration of diabetes on the risk of macrovascular and microvascular complications and death in type 2 diabetes. Diabetologia. 2014;57:2465-74.

38. Asano RY, Sales MM, Alberto R, Browne V, Fernando J, Nova V, et al. Acute effects of physical exercise in type 2 diabetes: A review. world J disbetes. 2014;5(5):659-65.

https://www.researchgate.net/publication/264923848 Acute

39. Thent ZC, Das S, Henry LJ. Role of Exercise in the Management of Diabetes Mellitus: the Global Scenario. PLoS One. 2013;8(11):1-8.

40. Thomas D, Ej E, Ga N. Exercise for type 2 diabetes mellitus (Review ). Cochrane Database Syst Rev. 2009;(1):10-1. http://www.thecochranelibrary.com

41. Yang D, Yang Y, Li Y, Han R. Physical Exercise as Therapy for Type 2 Diabetes Mellitus: From Mechanism to Orientation. Ann Nutr Metab. 2019;74(295):313-21.

42. Ababa A, Tekalegn Y, Addissie A, Kebede T, Ayele W. Magnitude of glycemic control and its associated factors among patients with type 2 diabetes at Tikur Anbessa Specialized. PLUS ONE. 2018;13(3):5-16. https://doi.org/10.1371/journal. pone.0193442

43. Kim J, Kwon H, Park Y, Lee J, Kim M, Yoon K, et al. Prevalence and Associated Factors of Diabetic Retinopathy in Rural Korea. J Korean Med Sci. 2011; 26:1068-73.

44. Haghighatpanah M, Sasan A, Nejad M, Haghighatpanah M, Thunga G. Osong Public Health and Research Perspectives Factors that Correlate with Poor Glycemic Control in Type 2 Diabetes Mellitus Patients with Complications. Osong Public Heal Res Perspect. 2018; 9(4):167-74.

45. Wallace TM, Matthews DR. QJM Poor glycaemic control in type 2 diabetes: a conspiracy of disease, suboptimal therapy and attitude. Q J Med. 2000; 93:369-74. 